\title{
"Ya no encuentro misterio en la simple intimidad de los personajes". Una mirada a la obra de Maximiliano Barrientos
}

Por Magdalena González Almada ${ }^{\mathbf{1}}$ Universidad Nacional de Córdoba (Argentina)

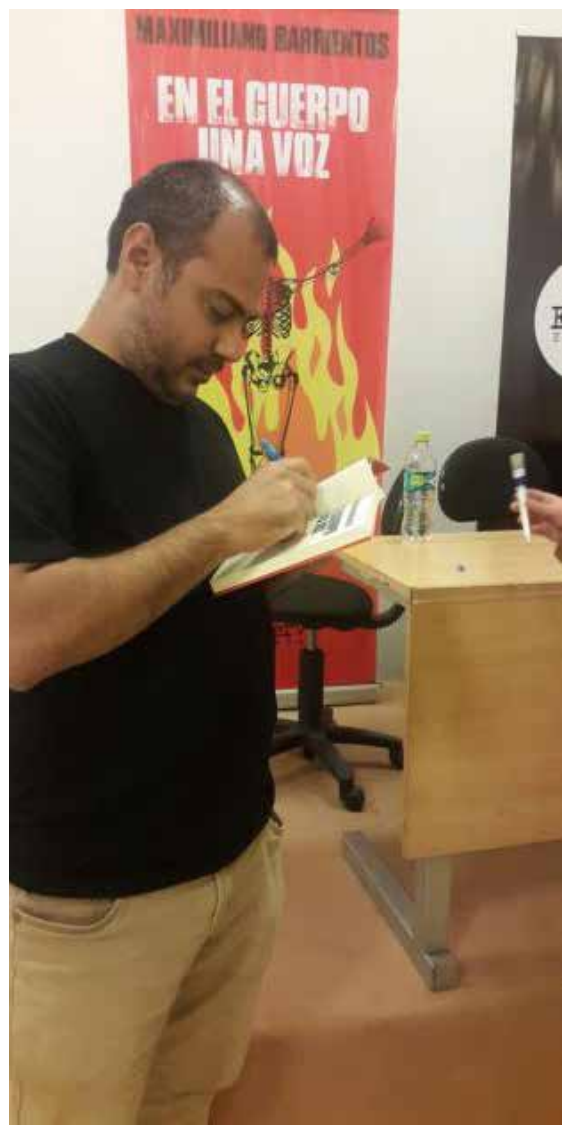

Maximiliano Barrientos nació en Santa Cruz de la Sierra, Bolivia, en 1979. En 2009, publicó Diario con la editorial El Cuervo. Sus volúmenes de cuentos Los daños (2006) y Hoteles (2007) fueron revisados y corregidos lo que dio como resultado el libro Fotos tuyas cuando empiezas a envejecer y Hoteles publicados por la editorial madrileña Periférica en el año 2011. Una casa en llamas, co-editado por El Cuervo y Eterna Cadencia (Argentina), apareció en el año 2015 al igual que la novela $L a$ desaparición del paisaje (2015, Periférica). En el año 2014 se graduó en el MFA de Escritura Creativa en Español en la Universidad de Iowa y en la actualidad se dedica a impartir clases referidas a la escritura en talleres y ámbitos académicos.

En esta entrevista le propusimos a Maximiliano realizar un breve recorrido por toda su obra atendiendo, también, a su novela más reciente -En el cuerpo una voz (2017)- que ha sido publicada en Bolivia, Argentina y México.

1 Doctora en Letras por la Universidad Nacional de Córdoba. Coordinadora del Grupo de Estudios sobre Narrativas Bolivianas. Correo electrónico: magdalenagonzalezalmada@hotmail.com 
El comienzo de tu carrera como escritor podría marcarse en 2009 con la publicación de Diario, un conjunto de cuentos publicados por la editorial El Cuervo. Incluso es el segundo título de esa editorial. ¿Cómo recordás esos momentos?

En realidad comenzó unos años antes, con la publicación en 2006 de Los daños y en 2007 de Hoteles, que salieron con La Hoguera. Ambos libros fueron reescritos y fueron publicados en España con Periférica en 2011. Creo que tienen una sintonía con Diario, comparten un mismo clima, una misma pulsión narrativa. En ese entonces me preocupaba por narrar lo que podríamos llamar intimidad, en cierta forma le encontraba una épica que poco a poco se fue perdiendo. Lo publiqué en El Cuervo porque entonces era una editorial nueva y me había hecho buen amigo de su editor. Y esa relación sigue hasta ahora, me parece una tremenda editorial que cambió el panorama en Bolivia.

Tanto en Diario (2009) cuanto en Fotos tuyas cuando empiezas a envejecer (2011) el cuento ha sido el punto de apoyo para narrar historias que, en apariencia, se presentan inconexas pero que están atadas a cierta presentación de una subjetividad que se pone en cuestión en los textos. ¿Considerás que tu escritura se siente más a gusto con el relato de historias íntimas, "pequeñas"?

Ahora ya no, la intimidad no me interesa, las búsquedas han cambiado significativamente, lo que espero se vea en algunos cuentos de Una casa en llamas y en la novela En el cuerpo una voz. Siempre he tenido un inmenso amor por el cuento, es un género que espero seguir practicando, pero ese mundo de historias pequeñas ahora me deja totalmente indiferente.

Reflexionando un poco sobre lo anterior, ¿creés que es necesario proseguir con la búsqueda de los grandes relatos?

Yo creo que un escritor tiene que escribir lo que en ese momento está en su cuerpo como una pulsión. Creo que la literatura viene de ahí, de ese ámbito no racional de donde provienen los sueños. A veces se da el caso de que esa pulsión está contaminada con una mirada sobre lo que es la situación nacional, sobre cómo se dan ciertas cuestiones sociales en momentos determinados. Otras veces eso no está de forma tan explícita. Supongo que pasa por qué clase de escritor sos, pero lo que importa es que la ficción responda a esa ansia, a ese llamado, y no al intento racional de contar una historia para explicar una época o un país.

Un espacio privilegiado en tus textos son los hoteles. En ellos, la subjetividad de los personajes parece "desvanecerse" o "suspen- 
derse", como si el hotel fuera un lugar al que deciden ir a refugiarse. ¿Creés que el hotel podría ser considerado como un nuevo "no lugar" en tu escritura?

Eso creo que estuvo presente en mis primeros textos con mucha fuerza, pero no estoy seguro que esa presencia se pueda encontrar en lo último que estoy escribiendo. El universo de En el cuerpo una voz es otro, quizás porque el registro de la intimidad y de las horas muertas, el escenario de esa cotidianidad, ya no es un presencia gravitacional. Ya no encuentro misterio en la simple intimidad de los personajes.

Tus personajes en muchos casos presentan una cierta ansiedad por la huida, por la evasión frente a situaciones dolorosas, extremas en algunos casos, que los atraviesan. ¿Qué tensiones planteás/imaginás en relación a la vacilación que se presenta entre un estar y un marcharse?

Eso también siento que fue parte de algo que se daba en los primeros libros, y que se cerró con La desaparición del paisaje. Ahora veo todo eso desde cierta distancia, la antena está captando otra clase de mensajes. Es como una vieja sensibilidad, por lo tanto me cuesta hablar de por qué estaba presente. Lo siento muy ajeno a lo que en este momento me preocupa.

¿Y en qué preocupaciones te centrás ahora?

-Supongo que la respuesta a esa pregunta está en lo que se narra el libro de cuentos Una casa en llamas y en la novela En el cuerpo una voz.

En tus textos se percibe fuertemente una relación entre espacio y cuerpo, como si fueran dos territorios donde se llevan a cabo todas las tensiones que planteás. Pienso, por ejemplo, en La desaparición del paisaje o en el cuento "No hay música en el mundo" (Una casa en llamas, 2015). ¿Qué lugar ocupa el cuerpo en tu escritura? ¿Creés que el cuerpo es un territorio en el que se imprimen emociones, frustraciones, etc?

El cuerpo es la única certeza que tenemos, pero al mismo tiempo es lo que más desconocemos, esa paradoja me resulta inquietante. En mis últimos textos siento que hay una exploración sobre estos dos puntos que crean una tensión, y por eso siento que la violencia es clave en las historias, porque actúa como el agente de una revelación. La violencia en muchas de mis historias es una forma de interrogar al cuerpo. 
En ese sentido, la expresión de la violencia ha ocupado en tu escritura un lugar importante pero siempre desde lo individual, lo íntimo. En tu novela En el cuerpo de la voz (2017) la violencia toma un rol más colectivo, más histórico, si se quiere. ¿Cómo ha sido ese viraje?

Creo que en el libro la violencia tiene un rol doble. Por un lado, cumple ese aspecto de revelación del que hablaba en la anterior respuesta pero también, cuando acontece dentro de una colectividad, lo que hace es volver superfluo al cuerpo. Lo cosifica, lo vuelve una especie de paisaje. No sé cómo se ha dado el viraje, pero en esta novela y en las cosas que estoy escribiendo ahora es una pulsión muy fuerte.

Tu nouvelle Hoteles (2007) fue traducida al portugués y publicada en Brasil. ¿Cómo fue tu experiencia con la traducción?

Fue una muy linda experiencia, ya que salió en una lindísima colección dirigida por el escritor Joca Reiner Terron. El título de la colección es Otra Lingua y salió en el sello Rocco. Estoy en compañía de autores que admiro mucho como Castellanos Moya y Ribeyro.

Tus novelas La desaparición del paisaje (2015) y En el cuerpo una voz (2017) han recibido una gran atención por parte de los medios especializados y por editoriales que se encuentran fuera de Bolivia. ¿Cuál es tu relación con estas casas editoriales? ¿Cómo percibís la difusión de tus textos en el extranjero?

Con mucha alegría y perplejidad.

Finalmente, una pregunta sobre tu ejercicio de docencia en los talleres de escritura creativa. En el año 2014 te graduaste de la Universidad de Iowa en el MFA de Escritura Creativa en español. ¿Cómo impactan estos estudios en tu escritura y en los talleres que impartís en Santa Cruz de la Sierra?

Los talleres de escritura te forman como lector, eso es lo más importante. No te enseñan a escribir, lo que hacen es que te permiten relacionarte con los textos de una forma distinta a como se relaciona el lector común o el lector académico. Leer como escritor es tratar de entender cómo funciona un texto, no qué cosa significa. Qué es lo que hace que un cuento funcione tan bien y qué hace que un relato cojee. Eso es fundamental. Después cada quien va a ir avanzando de acuerdo al talento y a la voluntad que tenga. 